\title{
DIMENSÃO PEDAGÓGICA DA EDUCAÇÃO FíSICA NO ÂMBITO DA SAÚDE
}

\author{
Andrea Carla de Paiva \\ Universidade Federal Rural de Pernambuco, Recife, Pernambuco, Brasil \\ Marcilio Souza Junior \\ Universidade de Pernambuco, Recife, Pernambuco, Brasil \\ Gustavo de Oliveira Gama \\ Universidade de Pernambuco, Recife, Pernambuco, Brasil \\ Ana Rita Lorenzini \\ Universidade de Pernambuco, Recife, Pernambuco, Brasil \\ Livia Tenório Brasileiro \\ Universidade de Pernambuco, Recife, Pernambuco, Brasil \\ Marcelo Soares Tavares de Melo \\ Universidade de Pernambuco, Recife, Pernambuco, Brasil
}

\begin{abstract}
Resumo
O artigo analisa como se constitui a dimensão pedagógica da Educação Física no âmbito da saúde, considerando os elementos didático-pedagógicos. A pesquisa de cunho qualitativo, tipo documental, analisou relatórios que trataram da observação de práticas de profissionais da Educação Física, em diferentes espaços públicos e privados, a partir da análise de conteúdo como caminho para as interpretações dos dados. Identificamos que a dimensão pedagógica, nas ações desses profissionais, é determinada pela articulação entre as teorias educacionais e pedagógicas constitutivas da prática, caracterizando assim, esta dimensão, como eixo da profissionalização na área da Educação Física.
\end{abstract}

Palavras-chave: Educação Física. Saúde. Intervenção.

\section{Introdução}

Partimos do pressuposto de que as práticas em saúde, materializadas através dos modelos de atenção e serviços, nas atividades de gestão das políticas, ou por meio de diagnósticos, planejamentos e intervenções específicos do campo das práticas corporais, estão diretamente envolvidas com a educação. 
a educação deve ser permanente em todos os espaços e momentos possíveis, ou seja, todas as vivências construídas devem ser orientadas pela ação pedagógica e reflexão crítica das condições de vida e de saúde (...) e o contexto político-econômico no qual estão inseridos (NICÁCIO MARTINEZ, 2007, p. 30).

Esta não é exclusividade da educação escolarizada, pois a prática educativa se materializa em diferentes tempos e espaços, portanto, em diferentes instituições sociais, culturais, recreativas, de cuidados corporais em saúde.

Benedetti e Santos (2012) afirmam que a área de saúde permite a integração dos diferentes bens e serviços, seja em educação, lazer, esporte ou assistência social, incorporados pelos serviços públicos (hospitais, centros de referência em saúde mental, reabilitação e assistência social, policlínicas, unidades básicas de saúde, academias de saúde e penitenciárias) e privados (planos de saúde, academias, clubes, clínicas de estética, clínicas de reabilitação, atendimento personalizado, empresas).

Isto exige novas estratégias de prevenção, controle de doenças e de promoção da saúde, entre elas, o processo de construção de ações intersetoriais, na construção coletiva de saberes, linguagens e práticas, sob o viés da saúde coletiva (CARVALHO, 2005), entendida como campo de saberes e práticas que toma como objeto as necessidades sociais de saúde, pelas quais são construídas as possibilidades interpretativas e explicativas dos fenômenos relativos ao processo saúde-adoecimento. Tal processo compreende algo dinâmico e contraditório, que envolve desde estruturas ideológicas até a singularidade dos sujeitos (NICÁCIO MARTINEZ e MATIELLO JÚNIOR, 2012).

Prado e Carvalho (2014, p. 593) entendem

[...] como fundamental problematizar essas questões no campo acadêmico denominado Educação Física, considerando que ele diz respeito a uma prática social, ou uma prática pedagógica, que pode promover encontros visando ações compartilhadas, construção de vínculos e, sobretudo, produção de saúde e, em última instância, de vida.

Para que as estratégias de articulação entre educação e saúde componham uma linha de cuidado integral e efetivo na Educação Física, precisamos identificar/conhecer/aprofundar quais são os referenciais, concepções de saúde, que alicerçam o saber/fazer dos profissionais da área e como as teorias educacionais e pedagógicas estão implícita e explicitamente nessas práticas.

O reconhecimento da dimensão pedagógica na atuação destes profissionais implica dialogar com as diferentes esferas educativas (técnica, humana, político-social, ética, cultural, epistemológica, dentre outras), haja vista que esta dimensão está sempre presente no debate acadêmico e espaços de intervenção. No entanto, ela apresenta dissensos, entre estes, o desequilíbrio entre o cenário das produções científicas, que acumula avanços em reflexões conceituais e os poucos estudos acerca da abordagem teórico-metodológica voltada à prevenção da doença e promoção da saúde de uma população ou indivíduos no campo de intervenção da Educação Física e Saúde. 
Nesse sentido, perguntamos: como se constitui a dimensão pedagógica da Educação Física no âmbito da saúde?

\section{Metodologia}

Para responder a nossa pergunta, realizamos uma pesquisa documental de cunho qualitativo (MINAYO, 2007), cujas fontes foram os relatórios do trabalho final da disciplina Tópicos em Saúde do Curso de Pós-Graduação Lato-Sensu em Educação Física Adaptada a Portadores de Doenças Crônico-Degenerativas e Idosos, cujo objeto de reflexão foi a atuação profissional de Educação Física na área da saúde. A disciplina se propôs a discutir a prática pedagógica, tendo como referência as teorias educacionais e pedagógicas, a fim de responder a seguinte questão: o que há de pedagógico na atuação dos profissionais de Educação Física na área da saúde?

Esses relatórios foram descrições de observação da prática de profissionais de Educação Física em diferentes espaços de atuação no contexto da saúde, feitos em grupos (duplas ou trios) que acompanharam três sessões de aulas para cada espaço de atuação, totalizando 75 sessões de aulas observadas, orientados por um roteiro de observação constando dos dados de identificação, da organização das práticas observadas e a relação profissional-usuário.

Estes relatórios totalizaram 25 documentos, os quais foram analisados a partir da técnica de análise de conteúdo, a partir de três fases: a) Na primeira, fizemos uma leitura de todos os relatórios entregues, para entender os nexos internos ao documento em si e sua relação com os outros; b) Na segunda, trabalhamos a construção de quadros analíticos com as informações apresentadas nos relatórios, buscando categorias que permitissem uma análise rigorosa das fontes; c) $\mathrm{Na}$ terceira, discutimos os achados da pesquisa dialogando com as referências de base para análise dos dados (BARDIN, 2011; SOUZA JÚNIIOR, SANTIAGO, TAVARES, 2010).

Nesse sentido, o Quadro I expressa como foi organizada e mapeada a descrição inicial dos Relatórios (R), seguida de uma numeração de acordo com a ordem em que foram feitas as inferências. As descrições se apresentam de forma agrupada pelas modalidades de práticas observadas, clientela privilegiada, doenças crônico-degenerativas identificadas e sobre os espaços de intervenção.

Cada documento correspondeu a uma prática observada de profissionais de Educação Física que tinham como perfil a formação em Licenciatura ou Bacharelado, atuando em instituições privadas ou públicas ligadas ao campo da saúde.

Quadro I - Síntese do mapeamento das descrições das práticas observadas

\begin{tabular}{|c|c|c|c|c|}
\hline No Documentos & $\begin{array}{c}\text { Atuação - práticas } \\
\text { corporais }\end{array}$ & $\begin{array}{c}\text { Clientela } \\
\text { privilegiada }\end{array}$ & $\begin{array}{c}\text { Doença crônico- } \\
\text { degenerativa }\end{array}$ & Espaço de Intervenção \\
\hline $\begin{array}{c}\text { R2, R12, R14, } \\
\text { R15, R16, R17, } \\
\text { R19, R22 }\end{array}$ & Hidroginástica & Idosos e adultos & Hãentificam & $\begin{array}{c}\text { Clubes, Academias de } \\
\text { Ginástica, SESI, SEST/SENAT, } \\
\text { Projetos Sociais e Hotel }\end{array}$ \\
\hline R18, R20 e R25 & Musculação & Idosos e adultos & Hipertensão & Academias de Ginástica \\
\hline $\begin{array}{c}\text { R1, R3, R4, R5, } \\
\text { R6, R8, R9, R10 } \\
\text { e R24 }\end{array}$ & Ginástica & Jovens e adultos & Não identificam & $\begin{array}{c}\text { Academias de Ginástica e } \\
\text { Programa Academia da Cidade }\end{array}$ \\
\hline $\begin{array}{c}\text { R7, R11, R13, } \\
\text { R21 e R23. }\end{array}$ & $\begin{array}{c}\text { Práticas outras } \\
\text { jatação, dança, } \\
\text { jogos, consciência } \\
\text { corporal, spining) }\end{array}$ & $\begin{array}{c}\text { Idosos, adultos, } \\
\text { adolescentes e } \\
\text { crianças }\end{array}$ & $\begin{array}{c}\text { Obesidade, diabetes, } \\
\text { hipertensão e } \\
\text { doenças respiratórias }\end{array}$ & $\begin{array}{c}\text { Escolas e Academias de } \\
\text { Ginástica. }\end{array}$ \\
\hline
\end{tabular}


Detivemo-nos às interpretações dos conteúdos originários das categorias que emergiram dos documentos, o que possibilitou a construção de outros quadros que revelaram, a partir das categorias analíticas - Teoria Educacional e a Teoria Pedagógica, os pilares da e para a reflexão conceitual, tanto no trato com a literatura, quanto no contato com os dados de campo, as unidades de significação das categorias empíricas.

Segundo Freitas (2011), uma Teoria Educacional formula uma concepção de educação e discute as relações entre educação e sociedade em seu desenvolvimento, explicando o papel dos sujeitos e da educação no mundo. Sobre a Teoria Pedagógica, o autor afirma que esta trata do trabalho pedagógico, formulando princípios norteadores e metodologias para organizar suas ações.

Nesse contexto, o Quadro II organiza as análises dos relatos das práticas observadas, e descreve, a partir das unidades de registro e de contexto ${ }^{65}$, as categorias empíricas advindas do contato com o campo, que por sua vez elucidam as categorias analíticas, permitindo o desmembramento e reagrupamento em núcleos de sentido:

Quadro II - Identificação das categorias analíticas

\begin{tabular}{|c|c|c|c|}
\hline \multicolumn{4}{|c|}{ CATEGORIZAÇÃO } \\
\hline \multicolumn{4}{|c|}{ Analítica - Teoria Educacional (Compreensão de homem, mundo e sociedade) } \\
\hline \multirow{4}{*}{ Empíricas } & Unidades de Contexto & Unidade de Registro & Relatos da Prática Observada \\
\hline & \multirow{3}{*}{$\begin{array}{l}\text { Teorias de Referência: } \\
\text { Não Crítica, } \\
\text { Crítico-Reprodutivista, } \\
\text { Crítica }\end{array}$} & Concepção de Professor & \\
\hline & & Concepção de Aluno & \\
\hline & & Concepção de Aula & \\
\hline \multicolumn{4}{|c|}{ Analítica - Teoria Pedagógica (Organização do Trabalho Pedagógico) } \\
\hline \multirow{3}{*}{ Empíricas } & Unidades de Contexto & Unidade de Registro & Relatos da Prática Observada \\
\hline & Elementos didático-pedagógicos & \multirow{2}{*}{$\begin{array}{l}\text { Objetivo/Avaliação } \\
\text { Conteúdo/Método }\end{array}$} & \\
\hline & Planejamento & & \\
\hline
\end{tabular}

As categorias empíricas que dialogaram com a categoria analítica Teoria Educacional foram agrupadas em Unidades de Contexto (Teorias de Referência) e de Registro (concepção de professor, concepção de aluno e concepção de aula). As Teorias de Referência tiveram apoio em Saviani (2009) que classifica as teorias em três campos: a) Não Crítica - centra-se na ideia de adaptar e ajustar os indivíduos à sociedade; b) Crítico-Reprodutivista - emerge da crença de que a educação termina por reproduzir as relações sociais vigentes; c) Crítica - analisa a sociedade e a educação como fenômeno social determinado em busca da transformação social.

As categorias empíricas elucidadas a partir da categoria Teoria Pedagógica foram o planejamento e os elementos didático-pedagógicos - Unidades de Contexto - e os pares dialéticos objetivo/avaliação e o conteúdo/método - Unidades de Registro. A partir daí, outros quadros foram construídos numa leitura flutuante, revisitando os documentos sempre que necessário, para garantir o rigor do método.

65 As unidades de contexto agrupam as unidades de registro codificando-as em temáticas mais amplas e as unidades de registro são as menores parcelas/dimensões da codificação. Com ambas é possível apreender a dinâmica do objeto de estudo e atribuir os sentidos de interpretação (BARDIN, 2011; SOUZA JÚNIIOR, SANTIAGO, TAVARES, 2010). 


\section{Resultados e discussões}

Organizamos os resultados e discussões nesse estudo em três tópicos:

a) A atuação profissional e as teorias educacionais de referência - neste tópico, o Quadro III explicita, de forma condensada, que as Teorias Educacionais que orientam as ações do profissional de Educação Física na saúde não se manifestam num único tipo de orientação teórica. Ora elas possuem um caráter tradicional, ora apresentam elementos tecnicistas, ou ainda elementos reflexivos na atividade desenvolvida ou almejam práticas mais críticas.

Quadro III - Características da dimensão pedagógica

\begin{tabular}{|c|c|}
\hline Práticas Observadas & Característica da Dimensão Pedagógica \\
\hline R13 e R23 & $\begin{array}{l}\text { São experiências com escolinhas de treinamento. Não há problematização do conteúdo } \\
\text { abordado na metodologia de trabalho, não são explicitados os objetivos e os conteúdos, e não } \\
\text { realiza uma avaliação em grupo. Metodologicamente, faz um aquecimento/alongamento, aula } \\
\text { propriamente dita (trabalha os fundamentos) e encerra com o recreativo (jogo). Destaca a } \\
\text { importância do planejamento do treino na organização do profissional. }\end{array}$ \\
\hline $\begin{array}{l}\text { R2, R12, R14, R15, } \\
\text { R16, R17, R19, R21 e } \\
\text { R22 }\end{array}$ & $\begin{array}{l}\text { São experiências com hidroginástica e dança. Existe adequação dos exercícios diante das } \\
\text { particularidades do grupo, realizando um diagnóstico e tendo o cuidado de explicar para quê e } \\
\text { por que das diferenciações, salientando instruções de segurança nos movimentos. No contexto } \\
\text { dos elementos didáticos identificam a adequação e linguagem, e a metodologia é feita a partir } \\
\text { do: aquecimento - caminhando dentro da piscina; Parte principal - saltos e elevação do joelho } \\
\text { com deslocamentos; relaxamento/alongamento. A recreação aparece como uma atividade } \\
\text { compensatória e a correção postural se caracteriza como ação avaliativa. }\end{array}$ \\
\hline $\begin{array}{l}\text { R3, R6, R7， R9， R10, } \\
\text { R11 e R24 }\end{array}$ & $\begin{array}{l}\text { São experiências com ginástica em Academias com destaque aos programas pré- } \\
\text { coreografados, com pouquíssimas possibilidades de adequação ao nível dos alunos com a } \\
\text { prescrição da atividade (frequência, intensidade, duração e tipo de exercício), e limitações } \\
\text { profissionais, pois não criam as aulas. O método de ensino se dá com adequação às dimensões } \\
\text { morfológicas, funcional-motora, fisiológica e comportamental, com foco no método da } \\
\text { demonstração. }\end{array}$ \\
\hline R1, R4, R5 e R8 & $\begin{array}{l}\text { São experiências com o Programa Academia da Cidade que apresenta um plano de ação de } \\
\text { base para a organização pedagógica, em que os profissionais problematizam o conteúdo com } \\
\text { o cotidiano dos usuários (Ex. as condições sociais de vida), alertando sobre a importância dos } \\
\text { exercícios, a adequação as faixas etárias, a orientação dos percursos de corrida e caminhada, a } \\
\text { realização de dinâmicas de grupo de relações interpessoais e palestras com os usuários. } \\
\text { Porém, este método não apresenta regularidade entre os profissionais, sendo registrado que } \\
\text { muitos destes utilizam o método da demonstração ou de práticas descontextualizadas. }\end{array}$ \\
\hline R18, R20 e R25 & $\begin{array}{l}\text { São experiências com a modalidade musculação. Os profissionais justificam a importância } \\
\text { das atividades como forma de facilitar a vida diária e proporcionar saúde, através do método } \\
\text { da demonstração. A organização das aulas se concentrará no diagnóstico sobre as condições } \\
\text { dos alunos para participação da aula, e a aferição da pressão arterial é utilizada como } \\
\text { instrumento. O aquecimento/alongamento é realizado, e a repetição das séries de exercícios } \\
\text { fundamenta a prática. }\end{array}$ \\
\hline
\end{tabular}

Os relatórios mostram que as evidências dessas práticas, no momento em que foram observadas, convergiram para aproximações/distanciamentos com as teorias de referência, porém, cada agrupamento com características pedagógicas específicas.

$\mathrm{Na}$ teoria de referência Não-Crítica, predominam as ações de ensino centradas na exposição do professor com sequências de aula predeterminadas. A ênfase está nos exercícios repetidos para garantir a memorização dos conteúdos:

No decorrer da aula, que é dividida por fases, em que a música tem importante papel propiciando ritmo aos movimentos, o professor instrui os alunos com 
relação à coreografia e cuidados a serem adotados [...]. O professor se posicionava o tempo inteiro de frente para os alunos, executando todo tempo os exercícios, coordenando, estimulando, orientando, liderando e interagindo com os alunos, proporcionando comunicação e alegria. (R10)

O que se percebe é que nas atividades de ginástica com base em coreografias pré-estabelecidas, os professores relatam a reprodução de movimentos de acordo com a mobilidade e o tempo de execução dessas aulas. As aulas apresentam "graus" de evolução, em que iniciantes e avançados cumprem num mesmo ritmo a atividade:

[...] o professor explicou como manusear a máquina Reformer (entrar e sair da máquina, utilização das molas, etc.) para que os alunos se adaptem a mesma. A aula foi iniciada mostrando e vivenciando a respiração utilizada, em seguida foi acrescentado os movimentos: membros inferiores com respiração, membros superiores com respiração e combinando membros inferiores e superiores com a respiração. Finalizou a aula com alongamento. (R24)

Desse modo, o que embasa esta prática é a teoria Não-Crítica mediante um jogo eficiente de estímulo e recompensa capaz de condicionar os praticantes com ações controladas e dirigidas pelo professor/profissional através de técnicas específicas.

Já a Teoria Crítico-Reprodutivista, apresenta em seu método de ensino o profissional num mesmo nível de importância em relação aos alunos, em que a ação é motivada pela codificação de uma situação problema.

A aula evidenciou ações pedagógicas como: adequação dos exercícios diante das particularidades dos alunos tendo o cuidado de explicar para que e o porquê das diferenciações do movimento; os propósitos dos exercícios explicados de forma motivante, salientando instruções de segurança, a fim de dar condições para a melhor realização dos movimentos. O professor pede que os alunos definam um circuito para que todos passem pelos exercícios. (R13)

Este relato indica que a aula, à medida que sinaliza a possibilidade de aprender com os sujeitos e com o profissional, com status de aula diferenciada, também responsabiliza os usuários sobre o que deve ser feito na aula, sem que conheçam o que é importante naquele momento. Contudo, indicativos de avanço também vão aparecendo:

A prática possui componentes pedagógicos, pois além de promover a adoção de um estilo de vida ativo, informando quais os benefícios do mesmo modo para uma melhor qualidade de vida, informa a seus usuários no que a atividade realizada contribui para seu dia-a-dia, partes componentes de seu corpo e como exercitá-las o que caracteriza o componente pedagógico, uma ação educativa para que o sujeito transporte para sua vida fora do ambiente do programa. (R5)

Essa intervenção envolve um programa de política de promoção de saúde relacionado às atividades físicas, fundamentado em princípios que buscam conduzir sujeito a refletir e atuar sobre 
as questões políticas, econômicas, sociais e pessoais, mas que se aproxima de elementos que estão entre a teoria Não-Crítica e Crítico-Reprodutivista, por não apontar/contextualizar a realidade dos usuários ou sobre os exercícios realizados:

Um dos professores de Educação Física iniciou a aula, um solicitou que os usuários fizessem um círculo para a realização dos exercícios de mobilidade articular, enquanto o outro ajudou na observação e correção dos erros de postura dos usuários. No segundo momento da aula (alongamento), um acadêmico pediu para que formassem duplas e ao sinal fizessem a troca das mesmas. No terceiro momento da aula (exercício de resistência muscular localizada), foi dada a ênfase aos membros superiores, na qual foram utilizados halteres e colchonetes. O final da aula ocorreu com os usuários deitados realizando movimentos de relaxamento. (R1)

Isto justifica a necessidade de uma intervenção pedagogizada e endossa o que Nogueira e Palma (2003) discutem, quando identificam que o problema da adesão às atividades físicas regulares de usuários está no distanciamento dos profissionais da realidade social dos sujeitos, considerando que o debate, em torno da adesão, não se encerra no interior do campo da Educação Física, mas inclui discussões mais amplas.

Nicácio Martinez (2007) e Nicácio Martinez e Matiello Júnior (2012), inserindo-se nesta discussão, buscaram outras possibilidades de compreensão da saúde do trabalhador e sua prática de atividade física. Aproximaram-se de teorias da Saúde Coletiva e da Epistemologia Crítica e investigaram uma intervenção pedagógica num projeto de educação em saúde de ginástica laboral.

Vemos, então, que identificar práticas com aproximações críticas ainda é um desafio. As possibilidades existem e poderão ser criadas no processo de sua (re)organização, de forma que profissionais e alunos se sintam convidados a submergir na realidade humanizada e crítica, já que metodologicamente ainda buscamos (re)construí-las no âmbito da Educação Física em relação à saúde.

b) A identidade docente e a prática pedagógica - Reconhecemos que a identidade docente é o ponto central nos documentos, e se expressa na utilização de termos bastante comuns ao campo escolar, como: o termo professor, tratado como sinônimo do termo profissional; e o termo aluno, em detrimento ao termo usuário.

A identidade docente, marcando as intervenções pedagógicas dos que atuam na saúde, tanto se dá pela formação generalista anterior às Diretrizes Curriculares Nacionais para Graduação em Educação Física (BRASIL, 2004), quanto nas atuais Diretrizes que definem o campo de intervenção nesta área e orientam para articulação entre as unidades de conhecimento de formação específica e ampliada em sua organização curricular, tendo na formação específica, a dimensão do conhecimento didático-pedagógica para os cursos de Bacharelado e Licenciatura.

Os estudos sobre identidade docente afirmam que o professorado de Educação Física que trabalha no Sistema Único de Saúde tem aspectos identitários distintos de outros coletivos docentes, vinculados a espaços profissionais diferentes, por exemplo os do Sistema Esportivo Nacional, os dos profissionais dedicados ao esporte de alto rendimento, e inclusive os de professores que trabalham na escola. 
Segundo Molina Neto et al. (2012, p. 519), a identidade docente na Educação Física se configura pelos campos de trabalho (educação, saúde, esporte), portanto, "é uma construção pessoal e social a qual tem relação com os processos de formação inicial e continuada [...] e com a experiência que os trabalhadores das diferentes especificidades disciplinares vivenciam nos contextos educativos".

No entanto, mesmo concordando com a ideia de que a identidade docente se constrói também no exercício da profissão e nas experiências dos sujeitos, acreditamos na dimensão pedagógica como eixo da profissionalização na área da Educação Física, reconhecida no campo da prática pedagógica, pois os próprios documentos revelam que, sejam bacharéis e/ou licenciados, a identidade pedagógica desses profissionais é tão expressiva que, as práticas em saúde também são denominadas de aula, por certo com características diferentes da aula do ambiente escolar.

A aula no contexto escolar é uma forma predominante de ensino-aprendizagem, um espaço/momento intencionalmente organizado para o desenvolvimento da reflexão pedagógica, por via da produção e apropriação do conhecimento, que, no campo de conhecimento da Educação Física, trata de temáticas específicas, que só se tornam possíveis, segundo Taffarel et al. (1995), abordando os objetivos, conteúdos, procedimentos de ensino, procedimentos avaliativos, locais/materiais, de maneira corresponsável.

A aula no âmbito da saúde, embora se constitua com os mesmos elementos didáticos, não cumpre com a mesma função social. Os objetivos daqueles que intencionam, procuram ou oferecem saúde por via das práticas corporais, não estão, necessariamente, relacionados com a sistematização de um conhecimento, como acontece na Educação Física escolar, mas com a apropriação/produção concreta em sua prática corporal mais imediata, ou seja, produzida no ato de sua realização, portanto sujeitos e não objetos da ação docente.

O que determina uma dimensão pedagógica é a articulação entre os elementos constitutivos da prática, presentes na organização de uma aula, que mesmo que o termo mais adequado fosse 'sessão', ali também estariam presentes os objetivos, conteúdos, procedimentos de ensino, procedimentos avaliativos, locais/materiais, situados numa determinada teoria de referência.

c) A composição dos elementos didáticos e o planejamento do profissional - Ao recorrermos a essas categorias, ressaltamos a importância dos elementos estruturantes de uma prática pedagógica, essencialmente nos elementos didáticos e no planejamento, vinculando conceitos de saúde a elementos operacionais da ação pedagógica.

Os poucos relatórios vinculados ao Programa Academia da Cidade apontam elementos sutis para a compreensão das práticas corporais como constituintes de uma saúde coletiva.

O ambiente é de total comunhão entre professores e alunos. Alunos estes, de idades diferentes, classes sociais diferentes, mas que, pelo que pudemos observar, deixam suas diferenças de lado e se unem por uma causa em comum, cuidar da saúde e se divertir. Aliás, apesar da disciplina em seguir todos os passos de uma aula, diversão é o que não falta... (R8)

De acordo com as necessidades vivenciadas com os usuários, quinzenalmente, são realizadas palestras de promoção à saúde, como também caminhada orientada como forma de interagir com a comunidade e transmitir informações sobre melhoria à sua condição de vida (R1) 
Implantados a partir de 2002 e localizados em áreas públicas os polos democratizam o acesso à prática das atividades físicas regulares, contando com a orientação de uma equipe de professores de Educação Física, Médicos e Nutricionistas (R4)

Vemos indícios para uma prática corporal mais alinhada ao cuidado e atenção integral à saúde do que propriamente à prescrição de exercícios físicos. As condições de vida, a construção de vínculos durante e a partir das atividades, aliam-se ao estado orgânico e à capacidade de resistir e enfrentar os fatores de risco e vulnerabilidade à saúde.

Segundo Cruz, Albuquerque e Damascena (2013) as atividades do Programa favorecem a vivência de práticas corporais tais como ginástica, dança, caminhada, corrida, jogos, brincadeiras, como também palestras, oficinas, reuniões e serviços de orientação nutricional, além da prescrição de exercícios e avaliação física. Todas realizadas por profissionais de Educação Física, juntamente com profissionais dos Núcleos de Apoio à Saúde da Família (NASF) e da Estratégia de Saúde da Família.

Percebemos também práticas corporais por dentro de ações e serviços públicos de ações com demonstração de intersetorialidade e envolvimento multiprofissional.

Porém, não há registros nos relatos, inclusive do Programa, que os sujeitos participantes das atividades chegam a ser problematizados acerca dos condicionantes sociais da saúde. As sutilezas não são suficientes, portanto para levar os sujeitos a pensarem mais amplamente sobre as necessidades da população acerca da saúde e menos ainda sobre as formas de organização para o enfrentamento dos problemas.

A visão hegemônica de saúde, na maioria absoluta dos relatórios, ainda lhe mantém vinculada à mera consequência de efeitos fisiológicos produzidos na prática das atividades físicas regulares que, segundo Bagrichevsky et al. (2006, p. 25), traz implicações ao campo do conhecimento e da intervenção, uma vez que essa adota um olhar distorcido da realidade e não leva em conta fatores contextuais relevantes a realidade social das pessoas.

Operacionalmente, nos objetivos das aulas descritos nos documentos, a hegemonia se dá sobre a questão da qualidade de vida ou a adoção de hábitos saudáveis, buscando o movimento relacionado à mobilidade articular, melhoria da condição cardiorrespiratória e grupos musculares explorados nas aulas.

Sob o olhar pedagógico no âmbito da saúde, a intervenção demonstra adaptação à realização regular da atividade física, implicando na participação dos componentes voltados às dimensões morfológicas (composição corporal, distribuição da gordura corporal), dimensão funcional-motora (função cardiorrespiratória, consumo máximo de $\mathrm{O}^{2}$, flexibilidade, força e resistência muscular localizada), dimensão fisiológica (pressão sanguínea, tolerância a glicose, sensibilidade insulínica, níveis de lipídeos sanguíneos e perfil das lipoproteínas), dimensão comportamental (tolerância ao estresse). (R14)

A forma como se definem os objetivos, automaticamente pressupõem uma meta a ser atingida pelo aluno-usuário, quase que numa relação de causa-efeito. 
Neste caso, as avaliações se voltam para o desempenho dos usuários, objetivam correções e adequações de exercícios. Os relatórios ressaltam os testes, as prescrições e as avaliações clínica, física e nutricional, com periodicidade regular, como forma diagnóstica e formativa:

Foi possível avaliar que a aula observada segue os padrões das aulas de hidroginástica encontradas na maioria das academias de ginástica [...].Grande preocupação na execução de exercícios para alcançar os objetivos propostos, mas tornando-se, às vezes, monótona e cansativa. Não há um feedback com os alunos. Eles apenas seguem as orientações da professora. São poucos os momentos de interação e sociabilização durante a vivência [...]. Não houve apresentação dos objetivos da aula e nem a avaliação da atividade no término, como exposto anteriormente. (R15)

Entretanto, os relatos indicam que a prescrição, além de ser uma forma de avaliação, também pode ser uma forma de planejamento registrado em fichas individuais, sendo formas de estabelecer previamente uma organização das ações de medir, julgar e decidir novas intervenções.

No medir o profissional faz uma anamnese (conversa inicial sobre histórico clínico cuidados especiais ou impedimentos com relação à saúde/adoecimento, casos na família experiências prévias com exercícios corporais, objetivos da atual atividade corporal, características individuais e ambientais a seu respeito, disponibilidade de tempo, hábitos alimentares, de tabagismo, de ingestão de álcool, etc) e faz uma avaliação física (dos perímetros corporais e das capacidades físicas).

Neste momento, poderíamos reconhecer novos indícios de um viés da saúde coletiva. No entanto, estes não ganham força diante das demais ações da intervenção, pois como já mostramos, não alcançam as dimensões dos determinantes sociais de saúde. Anamnese e avaliação física, com histórico clínico, com medida e teste corporal estão enraizadas no paradigma da aptidão física relacionada à saúde, bastante questionado pelos diálogos entre as áreas da Educação Física e Saúde Coletiva.

O professor iniciou a aula conversando com seus alunos para avaliar as condições físicas e psicológicas dos mesmos. Falou sobre a alimentação, verificou se tomaram os remédios de rotina e ressaltou a importância da atividade física na vida deles. (R18)

Com os dados da anamnese e da avaliação física, se compara os resultados para saber se o indivíduo está acima, abaixo ou na média, e, com a referência de determinados protocolos e testes anátomo-fisiológicos, faz o julgamento. Depois disso é decidir, verificando os tipos de exercícios adequados e prescritos, levando em consideração os princípios do treinamento.

As três ações dão continuidade de forma integrada, sempre medindo, julgando e decidindo, num acompanhamento sistemático, no dia-a-dia das exercitações por via da observação e anamnese, ou mesmo reavaliando mais detidamente, a cada três meses, reaplicando testes e revendo as medidas corporais.

O planejamento pode ser construído sob a perspectiva dos manuais dos programas ginásticos pré-coreografados de diferentes empresas: 
Os programas pré-coreografados têm sido o "boom" do novo milênio nas academias de ginástica. A padronização é um dos pontos de sucesso, o cliente sabe como será a atividade física, de que modo o professor deve se incorporar a qualidade dos resultados obtidos, independente do tamanho e da localização da academia. A certificação e o reconhecimento internacional, além de todo o marketing desenvolvido ao redor destes programas, transforma um círculo vicioso, no qual o professor de Educação Física amplia horizontes, valoriza mão-de-obra, e as academias crescem, gerando mais receita. As academias recebem um manual que ensina como usar os programas para aumentar as vendas e a retenção, e os professores as aulas prontas. (R6)

Além disso, os planejamentos podem ser construídos a partir da disponibilidade de horário para os profissionais planejarem as atividades propostas, além de trabalharem no formato de rodízio, garantindo o trabalho coletivo:

Os professores realizam um sistema de rodízio entre os conteúdos das aulas, onde cada um é responsável por uma ação. Enquanto um professor é responsável pelo alongamento, outro é responsável pelo exercício resistido e outro pela dança, porém, enquanto é realizado o alongamento, os professores responsáveis pelo exercício resistido e pela dança circulam pelo meio da aula auxiliando os alunos com dificuldade e assim sucessivamente, garantindo uma boa assistência a todos. (R8)

$\mathrm{Na}$ relação conteúdo/método, o método da demonstração é predominante utilizando a sequência: aquecimento, exercícios propriamente ditos e volta à calma; com aproximações aos métodos ginásticos (sessão preparatória, sessão propriamente dita e sessão de volta à calma).

Na introdução [...] um breve diálogo, seguido de um aquecimento, durante a aula foram realizados vários movimentos coreografados em cima e em volta do step, onde a coreografia era desenvolvida por partes segmentadas, em algumas sequências de movimentos dos alunos pareciam familiarizados com a mesma, por se tratar de uma turma avançada. Durante a aula o professor se utilizou do método demonstrativo para ensinar uma nova coreografia, verbalizando alguns movimentos de adução e abdução, extensão e flexão. (R9)

Podemos inferir, a partir das práticas relatadas, a preocupação dos profissionais em cumprirem seus objetivos, buscando sempre responder às demandas do processo saúde-doença pela prática em si das atividades corporais. No entanto, o processo é bem dinâmico e conflituoso, sendo necessário contrastar as necessidades individuais da saúde fisiológica com os condicionantes socioeconômicos de uma saúde coletiva. 


\title{
Conclusões
}

Enfim, destacamos que a dimensão pedagógica, como objeto de intervenção profissional, em Educação Física, se faz presente em diferentes espaços de atuação, inclusive no âmbito da saúde. Esta se expressa na forma como organiza e realiza o trabalho, e como está, explícita ou implicitamente, referenciada em uma teoria educacional e pedagógica, ainda que seu objetivo primeiro seja a busca de alterações anátomo-fisiológicas do aluno-usuário e/ou as ações intersetoriais para a saúde individual e coletiva.

Não podemos desprezar o componente específico que o profissional traz de suas diferentes experiências e particularidades do campo, seja de sua formação inicial ou mesmo da história e compreensão do campo, neste caso o da saúde, porém os elementos didáticos indicaram que a dimensão pedagógica se configura como eixo articulador da intervenção na área da Educação Física, apontando dados para a superação de um imaginário social e acadêmico de que o profissional de Educação Física no âmbito da saúde não teria uma identidade docente.

\section{PEDAGOGICAL DIMENSION OF THE PHYSICAL EDUCATION ON THE FIELD OF HEALTH}

\begin{abstract}
The paper analyzes how the pedagogical dimension of Physical Education constitutes itself on the field of health, considering the didactic-pedagogical elements. The qualitative documental research analyzed reports that treated the observation of professional practice in Physical Education, in different public and private spaces, taking content analysis as a path to interpretations. We identified that the teaching dimension in the actions of these professionals is determined by the link between educational and pedagogical theories that constitute practice, characterizing, therefore, this dimension as the axis of professionalism in Physical Education.
\end{abstract}

Keywords: Physical Education. Health. Intervention.

\section{DIMENSIÓN PEDAGógICA DE LA EDUCACIÓN FÍSICA EN LA SALUD}

\begin{abstract}
Resumen
El artículo analiza cómo constituye la dimensión pedagógica de la Educación Física en salud, teniendo en cuenta los elementos didácticos y pedagógicos. En la investigación cualitativa, por los documentos, fue analizado los informes que se ocupan de la observación de las prácticas de los profesionales de Educación Física en distintos espacios públicos y privados, a partir del análisis de contenido como una forma de interpretación de los datos. Se encontró que la dimensión pedagógica, en las acciones de estos profesionales, está determinada por la relación entre las teorías educativas y pedagógicas los cuales constituyen la práctica, caracterizando esta dimensión, como eje de profesionalismo en el campo de la Educación Física.
\end{abstract}

Palabras clave: Educación Física. Salud. Intervención. 


\section{Referências}

BARDIN, L. Análise de conteúdo. 6ª ed. São Paulo: Edições70, 2011.

BENEDETTI, T. R B.; SANTOS, S. F. S. Educação física no contexto da saúde. In. NASCIMENTO, J. V.; FARIAS, G. O. (Orgs.). Construção da identidade profissional em educação física: da formação à intervenção. Florianópolis: EDESC, 2001. p. 543- 556.

BRASIL. Ministério da Educação. Diretrizes curriculares nacionais para os cursos de graduação em educação física. CNE/CES. Resolução, n.7, Brasília: MEC, 2004.

BAGRICHEVSKY, M.; ESTEVÃO, A.; PALMA, A. Saúde coletiva e educação física: aproximando campos, garimpando sentidos. In. BAGRICHEVSKY, M.; ESTEVÃO, A.; PALMA, A.; DA ROS, M. (Orgs.). A saúde em debate na educação física - Volume 2. Blumenau. Nova Letra, 2006. p. 23-44.

CARVALHO, Y. M. Entre o biológico e o social: tensões no debate teórico acerca da saúde na educação física. Motrivivência, Florianópolis, ano XVII, n. 24, p. 97-107, jun, 2005.

CRUZ, D. A.; AlbuQuerQue, G.; DAMASCENA, W.. Programa Academia da Cidade do Recife: minimizando contrastes sociais. Recife (PE): Portal DSS Nordeste; 2013 Fev 06. Disponível em: <http://dssbr.org/site/experiencias/programa-academia-da-cidade-do-recifeminimizando-contrastes-sociais/?preview=true >. Acesso em 06 abr. 2015.

FREITAS, L. C. Crítica da organização do trabalho pedagógico e da didática. Campinas: Papirus, 2011.

MINAYO, M. C. S. O desafio do conhecimento: pesquisa qualitativa em saúde. São Paulo: Hucitec, 2007.

MOLINA NETO, V.; MOLINA, R. K; SILVA, L. O. O processo de identização docente e a formação em educação física para o trabalho docente no contexto da escola. In. NASCIMENTO, J. V.; FARIAS, G. O. (Orgs.). Construção da identidade profissional em educação física: da formação à intervenção. Florianópolis: EDESC, 2012. p. 519-542.

NICÁCIO MARTINEZ, J. F. Superações da educação (física) bancária pela saúde coletiva: pesquisa-ação no sindicato em Florianópolis. Dissertação (Mestrado em Educação Física) Universidade Federal de Santa Catarina, Florianópolis, 2007.

NICÁCIO MARTINEZ, J. F.; MATIELLO JÚNIOR, E.. Os limites da ginástica laboral para compreensão dos determinantes de saúde de trabalhadores bancários. Pensar a Prática, [S.1.], v. 15, n. 3, 3 2012. ISSN 1980-6183. Disponível em: <http://www.revistas.ufg.br/index.php/fef/article/view/13273/12077>. Acesso em: 11 Ago. 2014. 
NOGUEIRA, L.; PALMA, A. Reflexões acerca das políticas de promoção de atividade física e saúde: uma questão histórica. Revista Brasileira de Ciências do Esporte, Campinas, v. 24, n. 3, p. 103-119, 2003.

PRADO, A. R. do; CARVALHO, Y. M. de. SOBRE A VELHICE INSTITUCIONALIZADA: UM DESAFIO PARA A EDUCAÇÃO FÍSICA. Pensar a Prática, [S.1.], v. 17, n. 2, jun. 2014. ISSN 1980-6183. Disponível em: 〈http://www.revistas.ufg.br/index.php/fef/article/view/24110/16761〉. Acesso em: 18 Out. 2014.

SAVIANI, D. Escola e democracia. Campinas: Autores Associados, 2009.

SOUZA JÚNIOR, M., SANTIAGO, E., \& TAVARES, M.. A análise de conteúdo como forma de tratamento dos dados numa pesquisa qualitativa em educação física escolar. Movimento, 16 (3). 3149, 2010.

TAFFAREL, C. N. Z.; ESCOBAR, M. O.; FRANÇA, T. L. Organização do tempo pedagógico para a construção/estruturação do conhecimento na área de educação física e esporte. Motrivivência, Florianópolis, ano VII, n. 8, p. 124-132, dez., 1995.

Recebido em: 20/12/2014

Revisado em: 25/05/2015

Aprovado em: 09/06/2015

Endereço para correspondência:

Andrea Carla de Paiva

deapaiva8@gmail.com

Universidade Federal Rural de Pernambuco, Campus SEDE - Dois Irmãos - Recife.

Av. Dois Irmãos

Dois Irmãos

52171030 - Recife, PE - Brasil 